
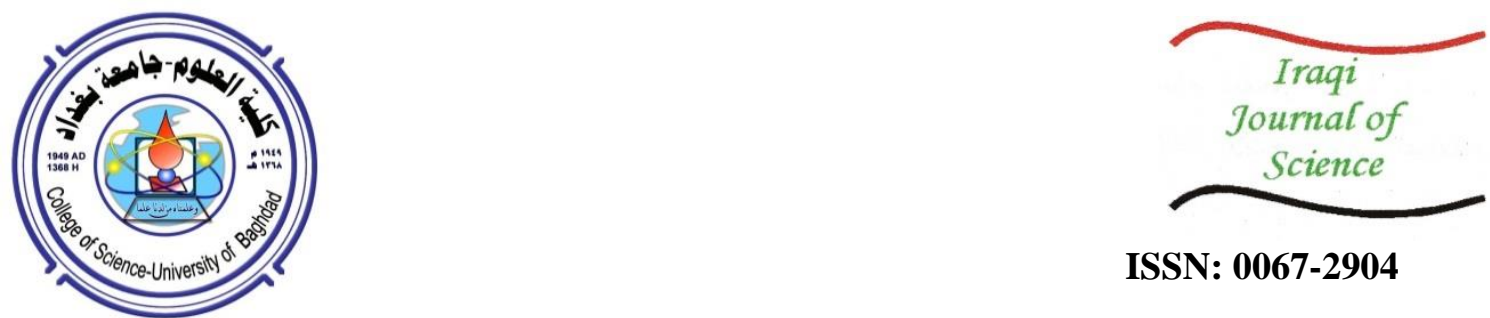

ISSN: 0067-2904

\title{
Detection of Albumin and Urea in Kidney Failure Patients by Optical Biosensor
}

\author{
Marwa .S. Alani*, Ithar Kamil Al-Mayaly \\ Department of Biology, Collage of Science, University of Baghdad, Baghdad, Iraq
}

Received: 6/12/2020

Accepted: 28/2/2021

\begin{abstract}
The major function of the kidney is the filtration and secretion of the final products of metabolism and the excess of electrolytes. The term kidney failure denotes inability of the kidneys to perform excretory function leading to retention of nitrogenous waste products from the blood. Biosensor are most accurate, with a rapid diagnosis ,more costly method than the traditional method to avoid any biological changes in blood sample that lead to changes optical characteristic (refractive index and absorption) of blood sample. The current study was designed to single mode more Sensitivity than multi mode for Biomarkers were recorded for Albumin 5447.06, 5193.93 and Urea sample 2623.14, 1998.44 in sm and $\mathrm{mm}$ respectively .
\end{abstract}

Keywords: kidney failure, Biomarkers, Biosensor.
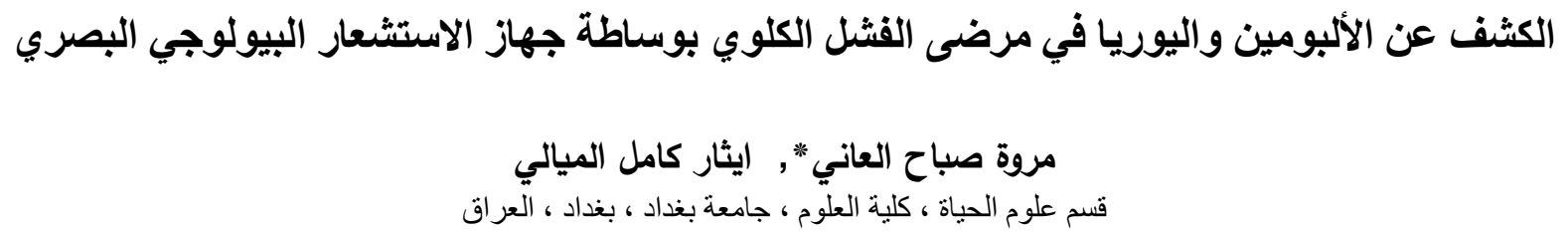

$$
\begin{aligned}
& \text { الخلاصة } \\
& \text { تتمثل الوظيفة الرئيسية للكلى في ترشيح وإفراز المنتجات النهائية لعملية التمثيل الغذائي وزيادة }
\end{aligned}
$$

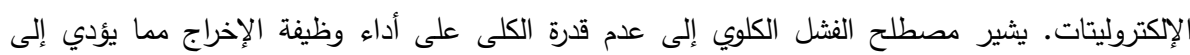

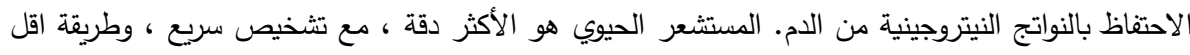

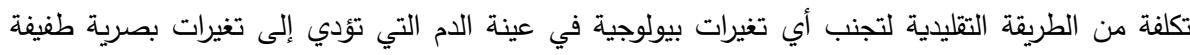

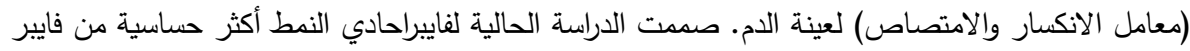

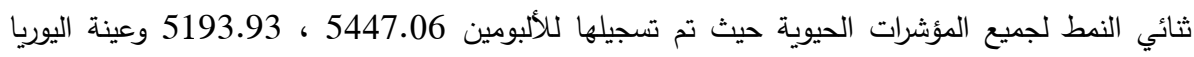

$$
\begin{aligned}
& \text { 2623.14 ، } 1998.44 \text { للفايير احادي النمط وثنائي النمط على التوالي. }
\end{aligned}
$$

\section{Introduction}

The major function of the kidney is the filtration and secretion of the final products of metabolism and the excess of electrolytes. Permanent failure of the kidney to accomplish its functions is called chronic kidney disease (CKD) and failure to sustain life, is called end stage renal disease [1]. Kidney failure is the stage of CKD at which a patient needs treatment with either dialysis or a kidney transplant to maintain life. Kidney failure occurs when glomerular filtration rate is less than 15 (CKD stage 5) [2]. Albumin is the major protein found in the 
blood. A healthy kidney does not let albumin pass into the urine. A injury kidney lets some albumin pass into the urine. Albumin in the urine is a sign of kidney damage [3].

Urea a waste product found in the blood that comes from the normal breakdown of protein in the body. It is normally removed from the blood by the kidneys and excreted in the urine. Urea builds up in the blood of people with severe kidney disease. High levels are associated with many adverse effects [4].

The field of optical biosensor reflect as multidisciplinary region of research that bonds the basic sciences principles (biology, physics and chemistry,) with essentials of medical application, nano-technology and its application in electronics. The history of biosensors demonstrated that the first 'true' biosensor was established by Leland C. Clark in 1956 [5] to detect oxygen and establish the first bubble oxygenator for tradition in cardiac surgery in 1962, he is identified as the 'biosensors father 'and the origination of the oxygen electrode bearings his name [6].

Kamil and Abu Baker 2015, designated a new type of biosensor expenses tapered type of single mode fiber with molecules bio recognition type to intelligence directed molecule of proteins. The interface of the evanescent waves with the outside average adjoining the area which is tapered products an interferometry-patterned spectrum, which changes similarly to variations of refractive index (RI) in the exterior medium [7].

\subsection{The objectives of this study are:}

1- Finding optical method alternative to traditional methods as indication to concentration of biomarkers.

2- Detection the effect of (Albumin and urea) optically by optical fiber sensor.

\section{Materials and Methods}

The present work includes the investigation of samples of biomarkers Albumin and Urea in age ranged from (40-72) years, females were (62\%) and males were (38\%). blood samples were admitted to Al- Kadhimiya and Medical City / Baghdad hospital complaining from Kidney Failure diseases.

\subsection{Spectral Absorbance Measurement}

The absorption spectra were measured using UV-spectrophotometer (SHIMADZU-UV2401PC), and spectra for all albumin and urea. Albumin has exhibited good absorption at 532 $\mathrm{nm}$. Hence for further study $532 \mathrm{~nm} \mathrm{Nd:} \mathrm{YAG} \mathrm{(green)} \mathrm{laser} \mathrm{was} \mathrm{used,} \mathrm{but} \mathrm{urea} \mathrm{has} \mathrm{exhibited}$ good absorption at $452 \mathrm{~nm}$ Hence for further study $452 \mathrm{~nm}$ (blue) laser was used as a source [8].

\section{Results and Discussion}

\subsection{Detection of the intensity of Albumin}

The intensity of Albumin of all samples and standard are measured using single mode, multimode biosensors as seen in the table (1).

Table 1-The measurement of intensity of Albumin using biosensors.

\begin{tabular}{|c|c|c|}
\hline $\begin{array}{c}\text { Sequence of Albumin } \\
\text { Samples from } \\
\text { higher to lower } \\
\text { concentration }\end{array}$ & $\begin{array}{c}\text { Intensity au } \\
\text { Single mode } \\
\text { Biosensor }\end{array}$ & $\begin{array}{c}\text { Intensity au } \\
\text { Multimode } \\
\text { biosensor }\end{array}$ \\
\hline Reference & $\mathbf{3 2 2 7}$ & $\mathbf{3 5 9 2}$ \\
\hline Standard & $\mathbf{2 3 1 6}$ & $\mathbf{2 5 3 1}$ \\
\hline 4.1 & $\mathbf{2 4 2 1}$ & $\mathbf{2 6 8 3}$ \\
\hline 4 & $\mathbf{2 4 3 1}$ & $\mathbf{2 7 3 7}$ \\
\hline 3.7 & $\mathbf{2 5 6 0}$ & $\mathbf{2 9 2 4}$ \\
\hline
\end{tabular}




\begin{tabular}{|l|l|l|}
\hline 3.6 & $\mathbf{2 6 4 8}$ & $\mathbf{3 0 1 1}$ \\
\hline 3.5 & $\mathbf{2 7 2 8}$ & $\mathbf{3 1 6 0}$ \\
\hline 3.4 & $\mathbf{2 9 2 7}$ & $\mathbf{3 2 4 7}$ \\
\hline 3.3 & $\mathbf{2 9 8 5}$ & $\mathbf{3 3 0 8}$ \\
\hline 3.2 & $\mathbf{3 0 5 5}$ & $\mathbf{3 3 9 5}$ \\
\hline 2.9 & $\mathbf{3 1 5 4}$ & $\mathbf{3 4 2 0}$ \\
\hline 2.6 & $\mathbf{3 3 4 2}$ & $\mathbf{3 5 2 0}$ \\
\hline
\end{tabular}

The initial intensity (reference) for single mode biosensor are $3227 \mathrm{au}$, for multimode are $3592 \mathrm{au}$. The highest intensity of Albumin in single mode is 3342 au and the lowest intensity are $2421 \mathrm{au}$. In multimode biosensor the highest intensity is 3520 au and the lowest intensity are $2683 \mathrm{au}$. The laser biosensors in $(1 \mathrm{~cm})$ length and $531 \mathrm{~nm}$ wavelength are used to measure the intensity spectra of Albumin. The intensity spectra of Albumin standard and the highest concentration of all Albumin sample in 2 types of biosensor (SM and MM) fibers are shown in figures (1) and (2), respectively.

\section{SM Albumin}

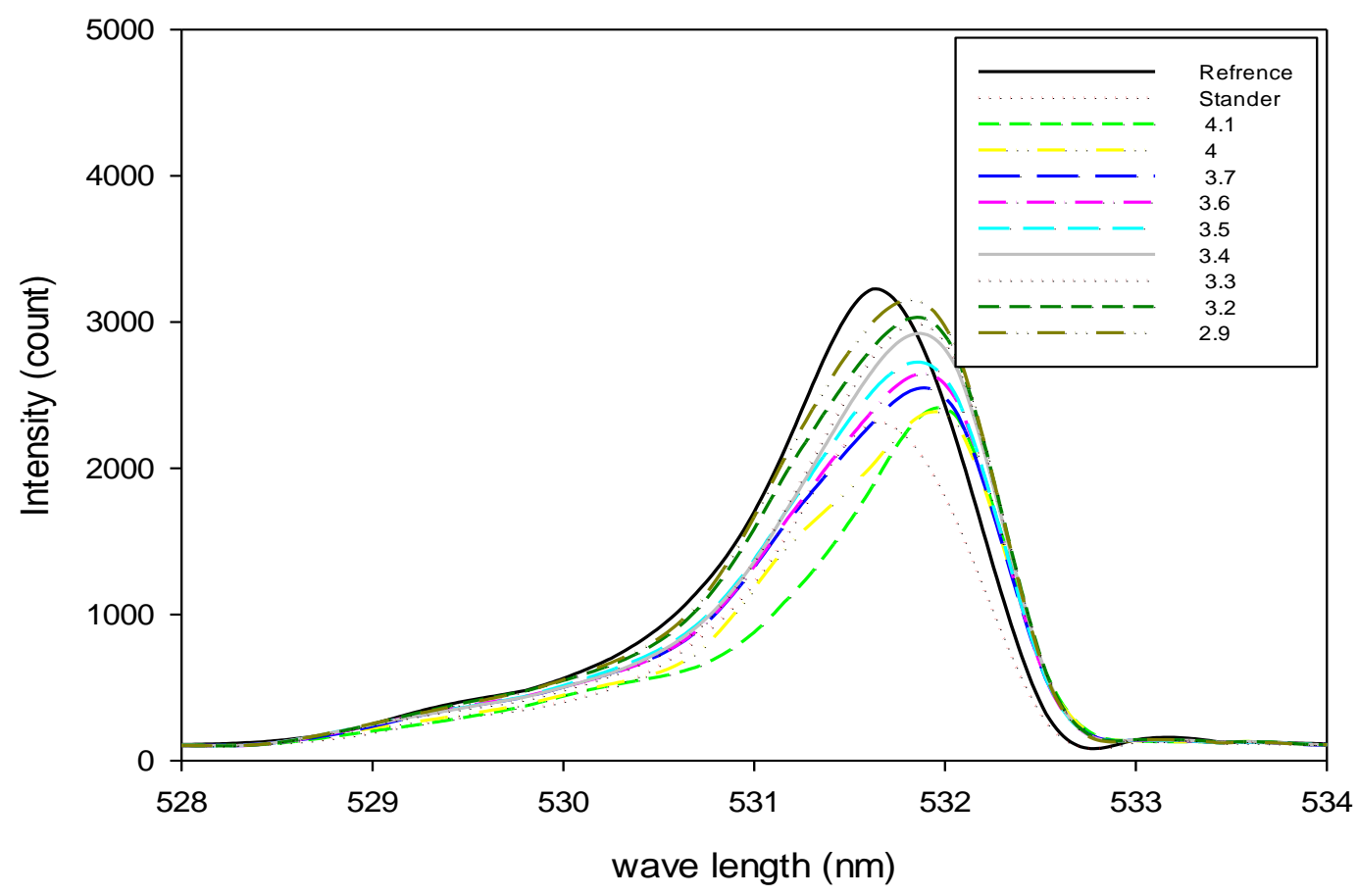

Figure 1-The intensity spectra of standard and different concentration (con.) of all samples for albumin in (SM) biosensor. 
MM Albumin

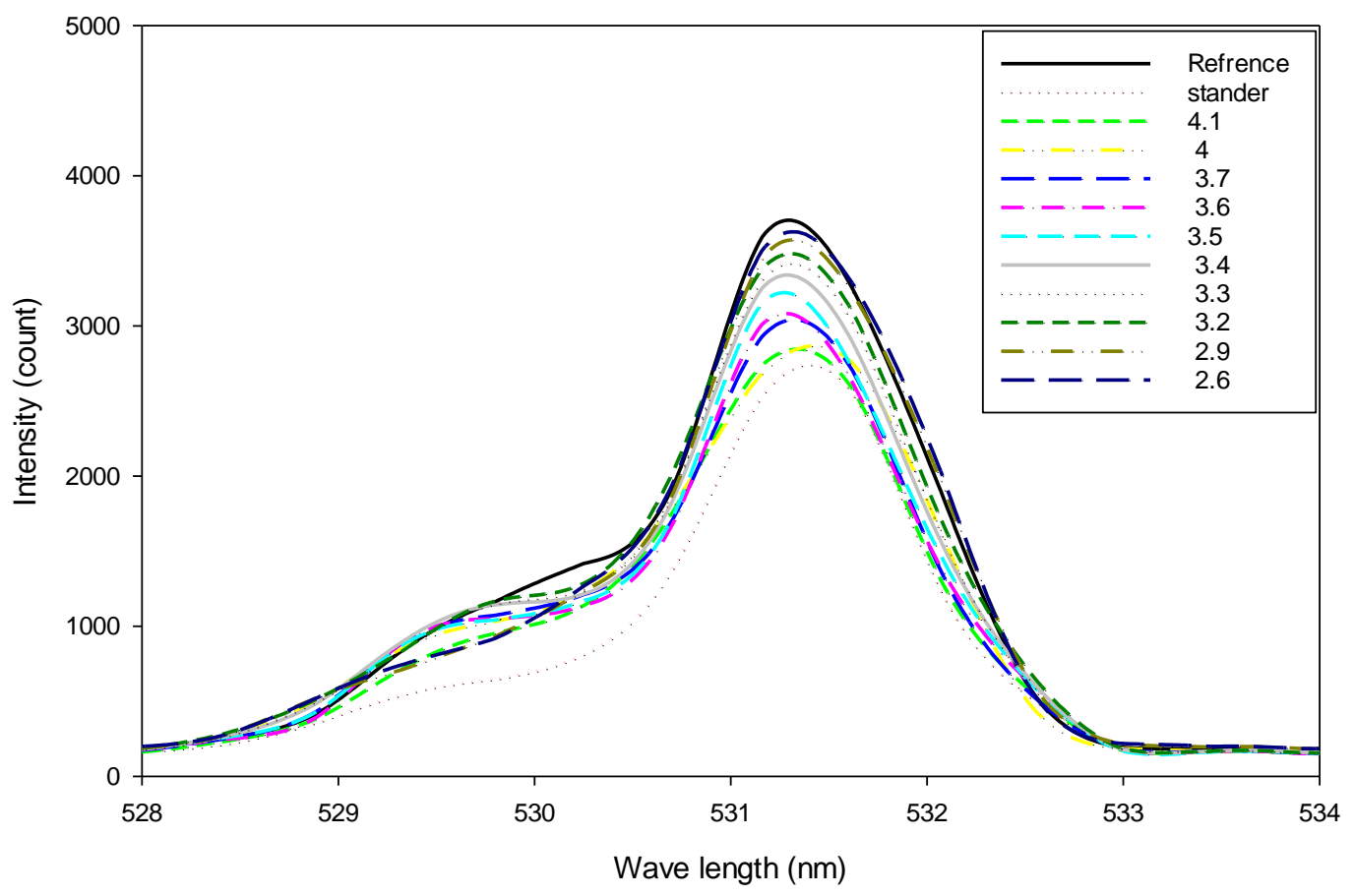

Figure 2-The intensity spectra of standard and different concentration (con.) of all samples for albumin in (MM) biosensor.

\subsection{Testing coincidence of Intensity among Studied Parameters:}

Analysis of variance has shown significant differences ** $(\mathrm{P}<0.01)$ between Effect of Albumin concentration in $\mathrm{mm}$ and sm Intensity. Also, LSD value (173.49**) shows highly significant differences between mm Intensity and samples concentration, LSD value (216.74 **) shows highly significant differences between sm Intensity and samples concentration and shows highly significant differences between $\mathrm{mm}$ and sm Intensity for each sample.

Table 2-Effect of Albumin concentration in $\mathrm{mm}$ and sm Intensity

\begin{tabular}{|c|c|c|c|}
\hline $\begin{array}{c}\text { Albumin } \\
\text { concentration }\end{array}$ & Intensity mm & Intensity sm & LSD value \\
\hline 4.1 & 2737 & 1873 & $128.05 * *$ \\
\hline 4 & 2683 & 2019 & $152.36 * *$ \\
\hline 3.7 & 2928 & 2308 & $141.88 * *$ \\
\hline 3.6 & 3009 & 2392 & $207.34 * *$ \\
\hline 3.5 & 3151 & 2525 & $163.27 * *$ \\
\hline 3.4 & 3251 & 2667 & $154.93 * *$ \\
\hline 3.3 & 3307 & 2760 & $136.71 * *$ \\
\hline
\end{tabular}




\begin{tabular}{|c|c|c|c|}
\hline 3.2 & 3378 & 2821 & $127.37 * *$ \\
\hline 2.9 & 3446 & 2996 & $122.64 * *$ \\
\hline 2.6 & 3501 & 3087 & $138.57 * *$ \\
\hline LSD value & $173.49 * *$ & $216.74 * *$ & -- \\
\hline \multicolumn{2}{|r|}{$* *(\mathrm{P}<0.01)}$. \\
\hline
\end{tabular}

A calibration curve between the albumin concentration and $\mathrm{mm}$ intensity is shown in figure (3). Figure (3) shows the intensity spectra at different concentration of albumin which leads to different refractive index RI values at $(1 \mathrm{~cm})$ single mode fiber length. The reduction in intensity is noticed when RI increased.

A calibration curve between the albumin concentration and sm intensity is shown in figure (4).

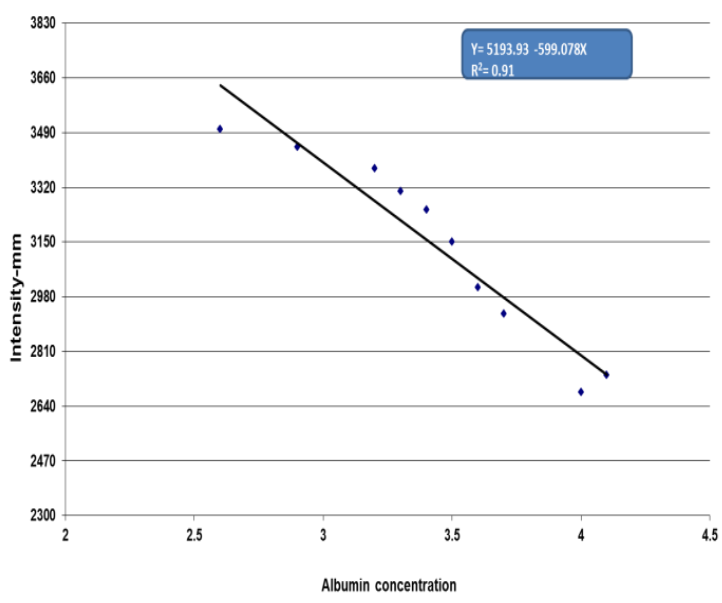

Figure 3 Relationship between Albumin concentration in $\mathrm{mm}$ Intensity

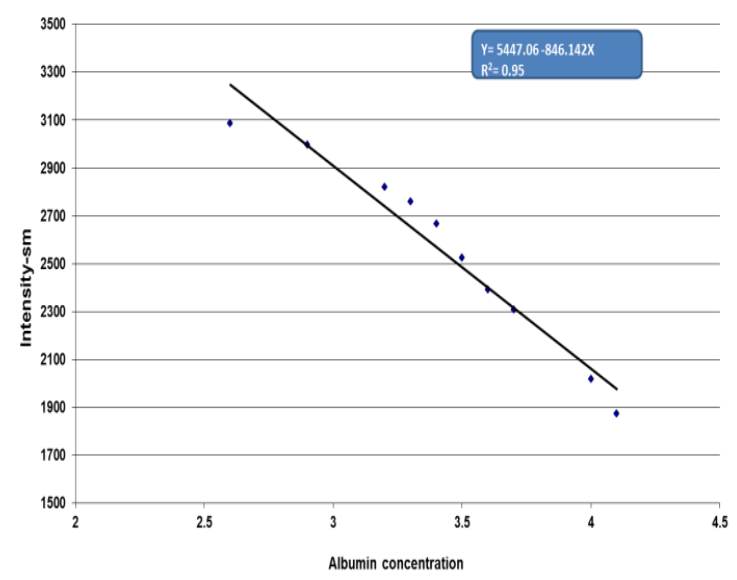

Figure 4 Relationship between Albumin concentration in sm Intensity

(Sensitivity = 5193.93 ABS/RIU).

(Sensitivity = 5447.06 ABS/RIU).

\subsection{Detection the intensity of Urea}

The intensity of Urea of all samples and standard are measured using single mode, multimode biosensors as seen in table (3).

Table 3-The measurement of intensity of Urea by using biosensors

\begin{tabular}{|c|c|c|}
\hline $\begin{array}{c}\text { Sequence of Urea } \\
\text { Samples from } \\
\text { higher to lower } \\
\text { concentration }\end{array}$ & $\begin{array}{c}\text { Intensity au } \\
\text { multi mode } \\
\text { biosensor }\end{array}$ & $\begin{array}{c}\text { Intensity au } \\
\text { single mode } \\
\text { biosensor }\end{array}$ \\
\hline Refrence & 2753 & 3354 \\
\hline Standard & 1983 & 2775 \\
\hline 277 & 1114 & 1384 \\
\hline
\end{tabular}




\begin{tabular}{|c|c|c|}
\hline 226 & 1176 & 1520 \\
\hline 206 & 1200 & 1586 \\
\hline 195 & 1280 & 1642 \\
\hline 192 & 1318 & 1649 \\
\hline 168 & 1411 & 1737 \\
\hline 107 & 1476 & 1861 \\
\hline 106 & 1490 & 1891 \\
\hline 94 & 1580 & 2034 \\
\hline 86 & 1602 & 2068 \\
\hline 83 & 1602 & 2119 \\
\hline 80 & 1736 & 2194 \\
\hline 77 & 1749 & 2321 \\
\hline 65 & 1804 & 2375 \\
\hline 54 & 1870 & 2475 \\
\hline 52 & 1934 & 2492 \\
\hline 51 & 1865 & 2501 \\
\hline 36 & 1945 & 2534 \\
\hline
\end{tabular}

The initial intensity (reference) for single mode biosensor is $3354 \mathrm{au}$, for multimode are 2753 au. The highest intensity of Urea in single mode are 2534 au and the lowest intensity are $1384 \mathrm{au}$. In multimode biosensor the highest intensity are 1945 au and the lowest intensity is $1114 \mathrm{au}$. The laser biosensors in $(1 \mathrm{~cm})$ length and 532nm wavelength are used to measure the intensity spectra of Urea. The intensity spectra of Urea standard and the highest and lowest concentration of all Urea sample in 2 types of biosensor (SM and MM) fibers are shown in figures (5) and (6), respectively. 


\section{SM Urea}

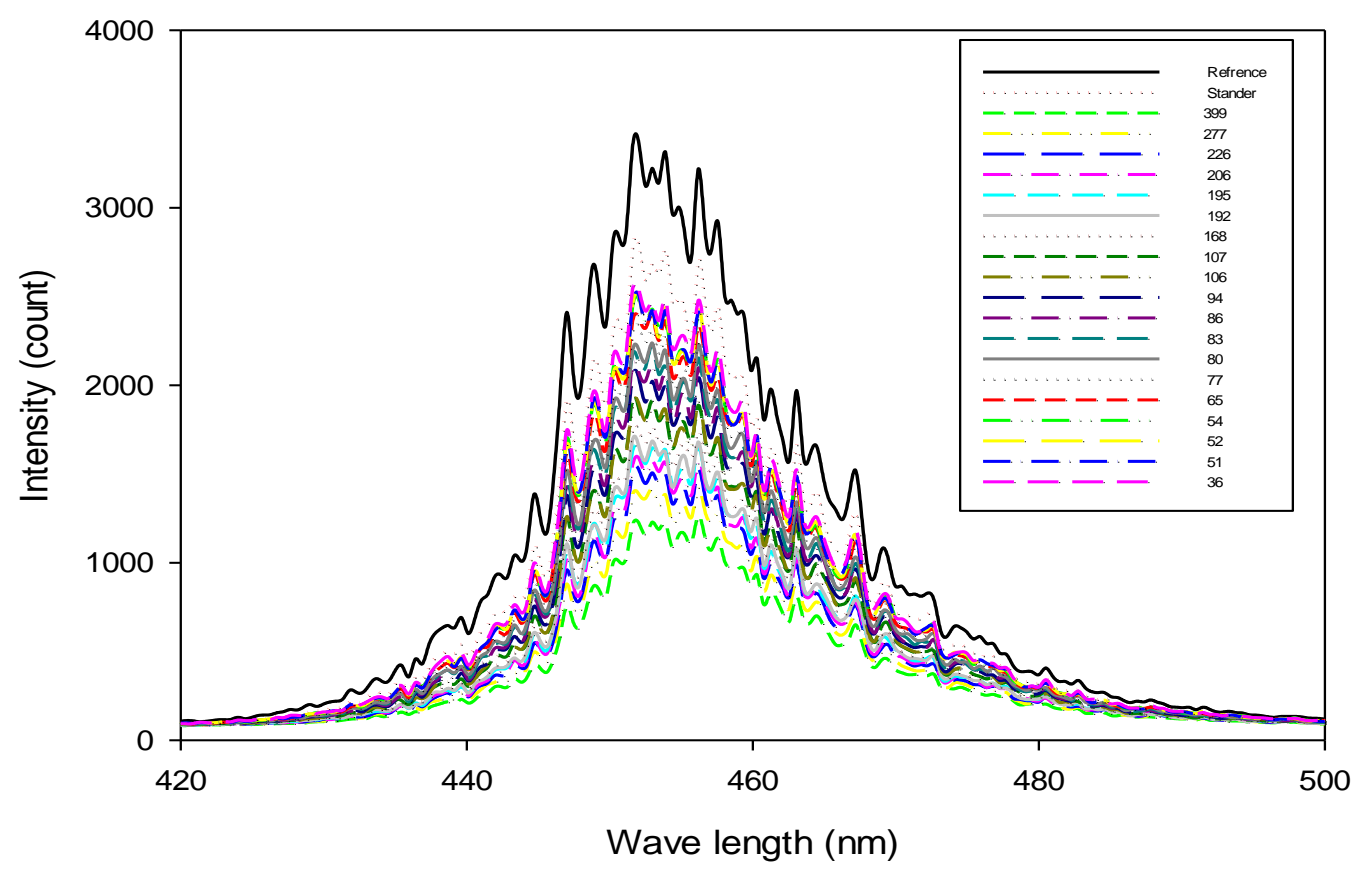

Figure 5-The intensity spectra at different concentration (con.) of urea of all samples at $(1 \mathrm{~cm})$ single mode length.

\section{Urea}

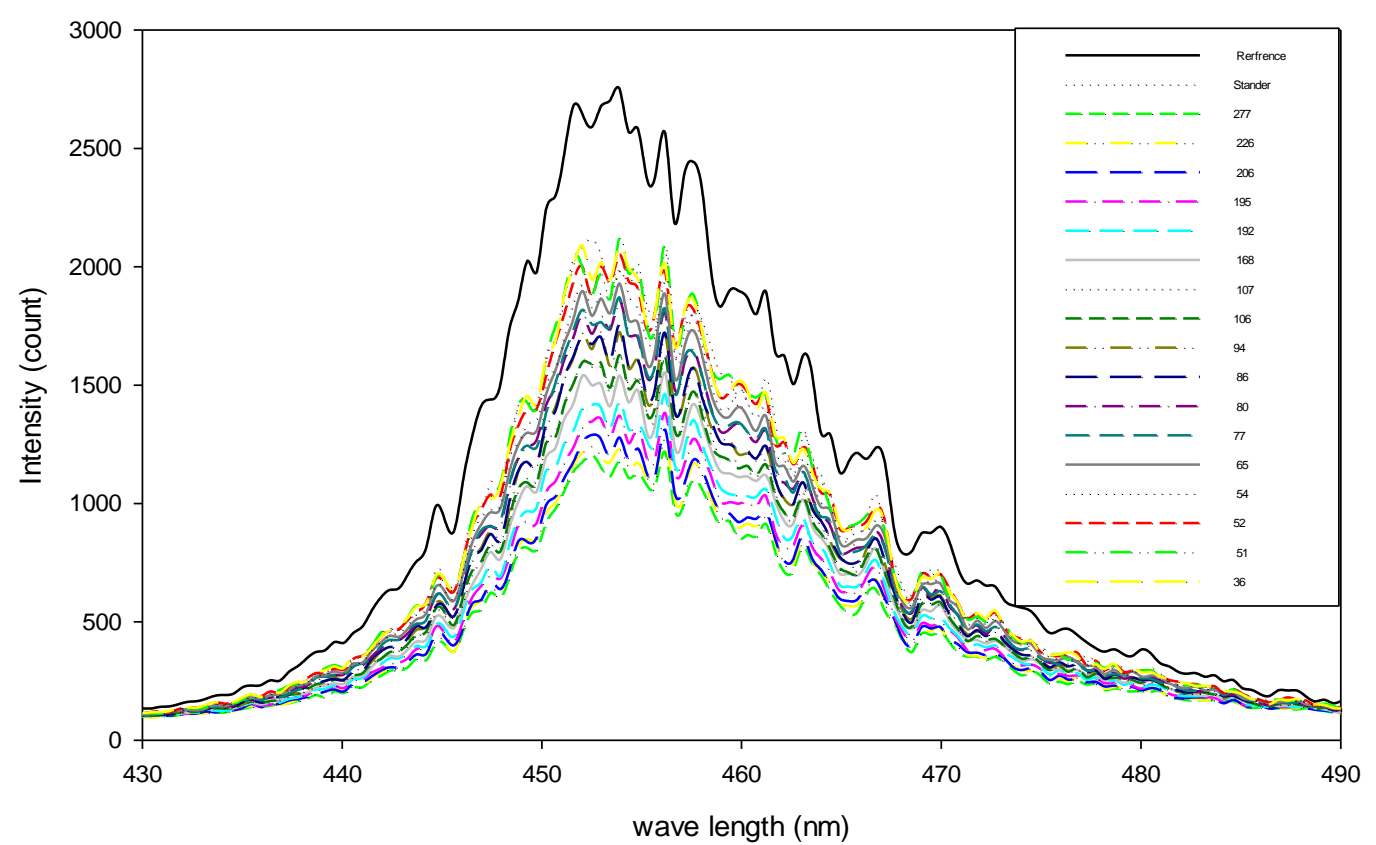

Figure 6-The intensity spectra at different number of urea concentration (con.) in all samples at $(1 \mathrm{~cm})$ multi-mode fiber length.

Highly significant effects $* *(\mathrm{P}<0.01)$ of sampling Urea concentration in $\mathrm{mm}$ and $\mathrm{sm}$ Intensity were found in analysis of variance of these values. However, LSD test gave a value indicating that most of these values were differed significantly from each other. 
Table 4 -Effect of Urea concentration in $\mathrm{mm}$ and sm Intensity

\begin{tabular}{|c|c|c|c|}
\hline Urea concentration & Intensity mm & Intensity sm & LSD value \\
\hline 277 & 1114 & 1384 & $85.32 * *$ \\
\hline 226 & 1176 & 1520 & $96.04 * *$ \\
\hline 206 & 1200 & 1586 & $87.14 * *$ \\
\hline 195 & 1280 & 1642 & $103.46 * *$ \\
\hline 192 & 1318 & 1649 & $81.93 * *$ \\
\hline 168 & 1411 & 1737 & $79.74 * *$ \\
\hline 107 & 1476 & 1861 & $112.36 * *$ \\
\hline 106 & 1490 & 1891 & $98.07 * *$ \\
\hline 94 & 1580 & 2034 & $109.35 * *$ \\
\hline 86 & 1602 & 2068 & $114.29 * *$ \\
\hline 83 & 1602 & 2119 & $120.86 * *$ \\
\hline 80 & 1736 & 2194 & $91.35 * *$ \\
\hline 77 & 1749 & 2321 & $95.03 * *$ \\
\hline 65 & 1804 & 2375 & $86.27 * *$ \\
\hline 54 & 1870 & 2475 & $116.42 * *$ \\
\hline 52 & 1934 & 2492 & $85.62 * *$ \\
\hline 51 & 1865 & 2501 & $91.44 * *$ \\
\hline 36 & 1945 & 2534 & $88.74 * *$ \\
\hline LSD value & $95.68 * *$ & $128.53 * *$ & --- \\
\hline
\end{tabular}

A calibration curve between the urea concentration and $\mathrm{mm}$ intensity is shown in figure (7). A calibration curve between the urea concentration and sm intensity is shown in figure (8). 


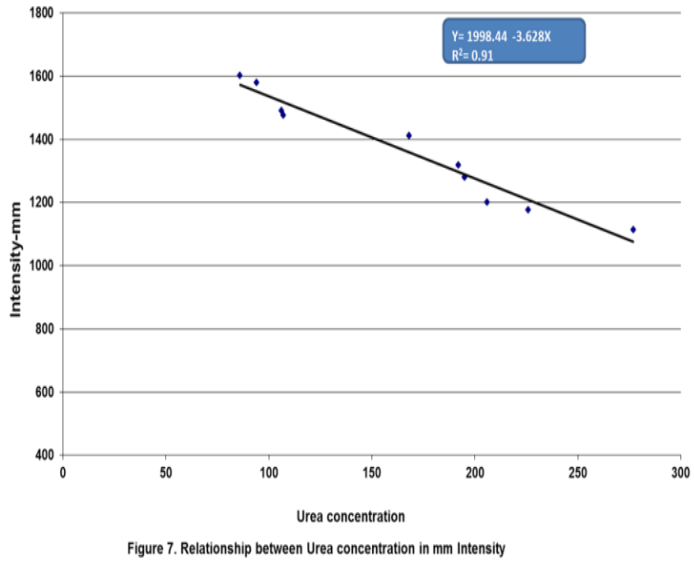

(Sensitivity = 1998.44 ABS/RIU).

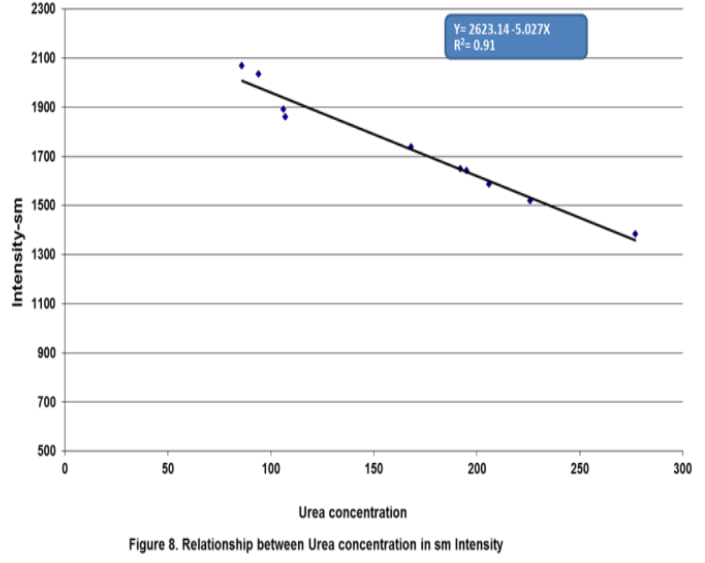

(Sensitivity = 2623.14 ABS/RIU).

Analysis of variance of these results reveals highly significant $* *(\mathrm{P}<0.01)$ impacts of both Correlation coefficient between $\mathrm{mm}$ and $\mathrm{sm}$ on Albumin and Urea. Furthermore, Correlation coefficient-r shows clear and significant differences between these data.

Table 5 - Correlation coefficient between multi mode and single mode

\begin{tabular}{|c|c|c|c|}
\hline Parameters & Intensity & Correlation coefficient-r & P-value \\
\hline Albumin & Mm and Sm & $0.98 * *$ & 0.0001 \\
\hline Urea & Mm and Sm & $0.99 * *$ & 0.0001 \\
\hline \multicolumn{3}{|c|}{$* *(\mathrm{P}<0.01)}$. \\
\hline
\end{tabular}

The current study in table (6) was designed to SM more Sensitivity than MM for all Biomarkers was recorded for Albumin 5447.06, 5193.93 in sm and mm respectively and Urea sample 2623.14, 1998.44 in sm and mm respectively .

Table 6 -Compare coefficient between Sensitivity of multi mode and single mode, sm more Sensitivity than mm for Albumin and Urea

\begin{tabular}{|c|c|c|}
\hline Biomarkers & Sensitivity (ABS/RIU) of SM & Sensitivity (ABS/RIU) of MM \\
\hline Albumin & 5447.06 & 5193.93 \\
\hline Urea & 2623.14 & 1998.44 \\
\hline
\end{tabular}

Typical biosensor is sensitive device that converts the biological change into a noticeable sign, later is then converted into a numerical signal consequence. The absorbance can be observed by directing a beam of radiation at the sample and noticing the intensity of emission that originates across it [9].

The obtaining results demonstrated that the absorption of laser light by highly concentrated samples are higher and inversely proportional to the intensity of light, means the intensity of light is high when the concentration of samples are low. This phenomenon could be explained as, the higher absorption of light by samples (Biomarkers) due to the selection of suitable laser which depends on the absorption of the samples to the wavelength of the laser. The 
refractive index regulates how much the route of light is resolved, or refracted, when arriving a material [10].

From the findings of the present study, The constructed biosensor are fastest response ,stable, more accurate , fair sensitivity and inexpensive when used in the measurement of the concentration of biomarkers, single mode (SM) optical fiber sensor to sense the biomarkers and a high sensitivity to the concentration of the biomarkers has been observed, because the mode patterns passing through that fiber are compatible with the energy transmission levels of the biomarkers, also single mode which have limitation number of modes due to their basic, while SM fiber selected for any wavelength benefit, SM few losses than MM.

The present study highlights the following conclusions, which includes: the Albumin sensing in wavelength $531.16 \mathrm{~nm}$ MM and sensing in wavelength $531.62 \mathrm{~nm}$ in SM setup. The Urea sensing in wavelength $453.88 \mathrm{~nm}$ MM and sensing in wavelength $452.04 \mathrm{~nm}$ in SM setup.

\section{Referance}

[1] N. Thomas, "Renal Nursing. University Studio Press, Thessaloniki," 2003. Available: https://www.hsj.gr/medicine/causes-and-complications-of-chronic-kidney-disease-in-patients-ondialysis.php?aid=2656\#1.

[2] I. Vlahogiannis, "Clinical nephrology and hypertension," Ed., Paschalidis, Athens, 2009. Available: https://www.hsj.gr/medicine/causes-and-complications-of-chronic-kidney-disease-inpatients-on-dialysis.php?aid=2656.

[3] D. J. Rowe, H. Bagga and P.B. Betts, "Normal variations in rate of albumin excretion and albumin to creatinine ratios in overnight and daytime urine collections in non-diabetic children," Br Med J (Clin Res Ed) 291, pp. 693-694, 2009.

[4] L. A. Stevens, J. Coresh, T. Greene and A.S. Levey, "Assessing kidney function: Measured and estimated glomerular filtration rate," New Eng J Med. 354, pp.2473-2483, 2006.

[5] J. W. Severinghaus and P.B. Astrup, "History of blood gas analysis. IV. Leland Clark's oxygen electrode," Journal of Clinical Monitoring, vol. 2, no. 2, p. 125, 1986.

[6] B. Nikhil, P. Jolly, N. Formisano and P. Estrela, "Introduction to biosensors Essays in Biochemistry," vol. 60, no.1, pp.1-8, June, 2016.

[7] Y. M. Kamil and M. H. Abu Bakar, "Sensitive and Specific Protein Sensing Using Single-Mode Tapered Fiber Immobilized With Biorecognition Molecules IEEE Photonics Journal," vol. 7, no. 6, pp.1-1, December, 2015.

[8] A. N. Dhinaa and P.K. Palanisamy, " Z-Scan technique: To measure the total protein and albumin in blood," J. Biomedical Science and Engineering, vol. 3, pp. 285-290, 2010.

[9] C. R. Lowe, "Biosensors. Trends in Biotechnology," vol. 2, no.3, pp.59-65, 1984.

[10] D. Bergstrom, A. Kaplan and J. Powell, "Laser Absorption Measurements in Opaque Solids," Presented at the 10th Nordic Laser Materials Processing (NOLAMP) Conference, Piteå, Sweden, August, p. 17-19, ed: A. Kaplan, published by Luleå TU, Sweden, 2005. 